\title{
Therapeutic versus neuroinflammatory effects of passive immunization is dependent on $A \beta /$ amyloid burden in a transgenic mouse model of Alzheimer's disease
}

S Sakura Minami ${ }^{1}$, Elkhansa Sidahmed ${ }^{2}$, Saba Aid ${ }^{3}$, Mika Shimoji $^{1}$, Takako Niikura ${ }^{2}$, Italo Mocchetti ${ }^{1}$,

G William Rebeck', Jay S Prendergast ${ }^{4}$, Chris Dealwis ${ }^{4}$, Ronald Wetzel ${ }^{5}$, Francesca Bosetti ${ }^{3}$, Yasuji Matsuoka ${ }^{2}$, Hyang-Sook Hoe ${ }^{1,2}$, R Scott Turner ${ }^{2^{*}}$

\begin{abstract}
Background: Passive immunization with antibodies directed to $A \beta$ decreases brain $A \beta$ /amyloid burden and preserves memory in transgenic mouse models of Alzheimer's disease (AD). This therapeutic strategy is under intense scrutiny in clinical studies, but its application is limited by neuroinflammatory side effects (autoimmune encephalitis and vasogenic edema).

Methods: We intravenously administered the monoclonal A $\beta$ protofibril antibody PFA1 to aged (22 month) male and female $3 \times \operatorname{tg} A D$ mice with intermediate or advanced AD-like neuropathologies, respectively, and measured brain and serum $A \beta$ and CNS cytokine levels. We also examined 17 month old $3 \times \operatorname{tg} A D$ female mice with intermediate pathology to determine the effect of amyloid burden on responses to passive immunization.

Results: The 22 month old male mice immunized with PFA1 had decreased brain $A \beta$, increased serum $A \beta$, and no change in CNS cytokine levels. In contrast, 22 month old immunized female mice revealed no change in brain $A \beta$, decreased serum $A \beta$, and increased CNS cytokine levels. Identical experiments in younger (17 month old) female 3 $\times \operatorname{tg} A D$ mice with intermediate AD-like neuropathologies revealed a trend towards decreased brain $A \beta$ and increased serum $A \beta$ accompanied by a decrease in CNS MCP-1.

Conclusions: These data suggest that passive immunization with PFA1 in $3 \times \operatorname{tg}$ AD mice with intermediate disease burden, regardless of sex, is effective in mediating potentially therapeutic effects such as lowering brain $A \beta$. In contrast, passive immunization of mice with a more advanced amyloid burden may result in potentially adverse effects (encephalitis and vasogenic edema) mediated by certain proinflammatory cytokines.
\end{abstract}

\section{Background}

A defining pathological hallmark of Alzheimer's disease $(\mathrm{AD})$ is the accumulation of $\mathrm{A} \beta /$ amyloid deposits in brain. The generation and clearance of $A \beta$, produced from amyloid precursor protein (APP) by $\beta$ - and $\gamma$-secretases, remain key therapeutic targets for transgenic AD mouse models and for clinical studies [1]. $A \beta$ naturally exists as a monomer or as aggregates including oligomers,

\footnotetext{
* Correspondence: rst36@georgetown.edu

${ }^{2}$ Department of Neurology, Bldg. D, Suite 177, Georgetown University Medical Center, 4000 Reservoir Road NW, Washington, DC 20057, USA Full list of author information is available at the end of the article
}

protofibrils, and fibrils. Of the two most commonly generated isoforms of $A \beta, A \beta 40$ and $A \beta 42$, the latter aggregates more readily to form amyloid fibrils [2,3]. Oligomers and protofibrils, the intermediate stages of $A \beta$ fibril formation, are neurotoxic in culture and in animal models [4-6] and these aggregates may correlate better with $\mathrm{AD}$ severity than neuritic plaque density $[7,8]$.

Immunotherapy is an effective method of reducing brain $A \beta$ levels and preserving or improving behavioral outcome measures in transgenic mouse models of AD. Initial studies utilized an active immunization approach. Peripheral injections of synthetic human $A \beta$ prevented 
amyloid deposition, decreased CNS A $\beta$ /amyloid burden, and ameliorated memory deficits in mice [9-11]. However, when this therapy was translated to individuals with $\mathrm{AD}$, the pivotal clinical trial was terminated early due to the development of excessive neuroinflammation (autoimmune encephalitis) in 6\% of treated individuals [12]. Passive immunization with antibodies to $A \beta$ may offer a safer, and reversible, alternative by circumventing $T$-cell responses associated with neuroinflammation in active immunization protocols. Passive immunization studies show similar efficacy in reducing brain $A \beta / a m y-$ loid and preserving memory in transgenic mouse models of $\mathrm{AD}[13,14]$, but the passive immunization approach is also limited by excessive neuroinflammation and vasogenic edema in a subset of treated individuals with AD.

Passive immunization may reduce brain $A \beta$ by at least two distinct mechanisms that are not mutually exclusive: 1) microglial phagocytosis of $A \beta /$ amyloid with increased cytokine production, which requires peripherally administered antibodies to cross the blood brain barrier [13], and 2) peripheral sequestration of $A \beta$ by antibody in the blood - referred to as the sink hypothesis [14]. The $A \beta$ antibody in the periphery may act as a sink by binding $A \beta$ in the blood and promoting clearance of $A \beta$ from the brain to the periphery, resulting in increased plasma $A \beta$ following treatment. Others suggest, however, that peripherallyadministered antibody also prolongs the half-life of $A \beta$ in blood, and this explains the resultant increase in plasma levels. To examine these possibilities, it is important to measure CNS cytokine levels in addition to serum and brain $A \beta$ levels following passive immunization. It is unknown whether immunotherapy may prove beneficial with high levels of CNS amyloid burden, or whether treatment may perhaps be limited to a subset of individuals in earlier disease stages. Alternatively, antibody dosage may be tailored to amyloid burden in order to minimize the risk of encephalitis and vasogenic edema. A recent clinical study reported increased vasogenic edema with higher antibody dosage and greater disease burden (as found in ApoE4-positive subjects) [15]. This is the first study to suggest differential responses to passive immunization perhaps due to CNS amyloid burden in a transgenic mouse model of AD.

We examined whether passive immunization of $3 \times$ tg $A D$ mice with the monoclonal $A \beta$ protofibril antibody PFA1, which is well-characterized but has not yet been tested as an immunotherapeutic [16,17], was effective in lowering brain $\mathrm{A} \beta$. The use of $3 \times \operatorname{tg} \mathrm{AD}$ mice (which express three human mutant transgenes-APP, PS-1, and Tau-found in familial AD or a familial tauopathy) allowed us to investigate CNS A $\beta$ levels as well as downstream effects of PFA1 immunization on tau phosphorylation. The $3 \times \operatorname{tg} \mathrm{AD}$ mice are also known to have sex-specific differences in CNS amyloid burden, where females develop $\mathrm{A} \beta$ pathology at an earlier age and to a much greater extent than males [18]. This allowed us to investigate the potential roles of sex and amyloid burden in response to passive immunotherapy. Passive immunization of intermediate but not more advanced stage $3 \times \operatorname{tg}$ AD mice resulted in decreased brain $A \beta$ and increased serum $A \beta$, supporting the sink hypothesis. In the older female mice with advanced pathology we found no change in brain $A \beta$ and an increase in CNS proinflammatory cytokine levels. Collectively, these data suggest that the potential benefits of passive (and active) immunization may be optimal in individuals with less pathology, and that treatment of individuals with more advanced CNS amyloid burden may engender potentially deleterious neuroinflammation. Passive (and active) immunization therapies may require tailoring to $A \beta /$ amyloid disease burden, and may be considered high risk in subpopulations with advanced disease due to the development of neuroinflammation, encephalitis, and vasogenic edema. The critical mediators of neuroinflammation in response to passive immunization in tg $\mathrm{AD}$ mice or in man, however, remain unclear.

\section{Methods \\ Animals}

We obtained $3 \times \operatorname{tg}$ AD mice (breeding pairs) from $\mathrm{Dr}$. Frank LaFerla (University of California, Irvine) to establish our colony. These mice were generated by comicroinjection of mutant APP (K670M/N671L) and tau (P301L) transgenes under the control of the Thy 1.2 promoter into mutant PS-1 (M146V) knock-in mice [19]. We used $3 \times \operatorname{tg} \mathrm{AD}$ mice at $21.6 \pm 0.5$ months of age for vehicle (PBS)-treated females $(n=6)$, PFA1-treated females $(n=7)$, vehicle-treated males $(n=5)$, and PFA1-treated males $(n=7)$. We also used $3 \times \operatorname{tg}$ AD mice at $16.8 \pm 0.6$ months of age for vehicle-treated females $(n=5)$ and PFA1-treated females $(n=5)$. Mice were sacrificed by cervical dislocation to eliminate anesthesia-mediated tau phosphorylation [20], and brains were snap-frozen in dry ice for biochemical analyses. All animal experiments were approved by the Institutional Animal Care and Use Committee at Georgetown University.

\section{Antibodies and chemicals}

The protofibril A $\beta$ monoclonal antibody PFA1 was purified as described [16,17]. The monoclonal antibody 6E10 was purchased from Invitrogen (Carlsbad, CA). Phospho-tau antibodies AT8 (Ser202/Thr205) and AT180 (Thr231) were purchased from Pierce Biotechnology (Rockford, IL), and Tau46 detecting total tau was purchased from Sigma-Aldrich (St. Louis, MO). Synthetic $A \beta 40$ and $A \beta 42$ were purchased from American 
Peptide (Sunnyvale, CA) and a fraction was dissolved to a concentration of $0.1 \mu \mathrm{g} / \mu \mathrm{L} d \mathrm{ddH}_{2} \mathrm{O}$ for gel loading for immunoblots.

\section{Mouse treatments and plasma collection}

Purified PFA1 (100 $\mu \mathrm{g}$ IgG/mouse) or vehicle control (PBS) was intravenously administered into the tail vein weekly for 4 weeks. Blood was collected from the facial vein 1 day prior to the first infusion and from the heart 1 week following the last injection - at the time of sacrifice. EDTA-treated plasma was prepared, aliquoted, snap frozen, and stored at $-80^{\circ} \mathrm{C}$ for biochemical assays.

\section{Sample preparation and $A \beta$ ELISAs}

Brains were homogenized in a 10 -fold volume of $50 \mathrm{mM}$ Tris- $\mathrm{HCl}$ buffer, $\mathrm{pH} 7.6$, containing $250 \mathrm{mM}$ sucrose and protease and phosphatase inhibitors. This crude brain homogenate was used for immunoblot analysis.

Proteins for immunoblot analysis of tau were separated on a $4-15 \%$ gradient Tris-HCl SDS-PAGE gel and transferred to a PVDF membrane. A $\beta$ samples were separated on a $10-20 \%$ gradient Tris-Tricine gel (BioRad, Hercules, CA). The membrane was blocked with $5 \%$ non-fat dry milk and probed with the appropriate primary antibody and HRP-coupled anti-mouse IgG secondary antibody (Jackson ImmunoResearch, West Grove, PA). Bands were visualized using a chemiluminescence kit (Pierce, Rockford, IL) and densitometrically quantified (Quantity One, BioRad).

Soluble A $\beta$ was extracted in $0.4 \%$ diethylamine (DEA) as previously described [21]. Briefly, crude $10 \%$ homogenate was mixed with an equal volume of $0.4 \%$ DEA, sonicated, and ultracentrifuged for 1 hour at 100,000 $\times$ g. The supernatant was collected and neutralized with $10 \% 0.5 \mathrm{M}$ Tris base, $\mathrm{pH}$ 6.8. The resulting DEA fraction was used for soluble $A \beta$ analyses. For analysis of 22 month old mice, total $A \beta$ was analyzed from $10 \%$ crude brain homogenate mixed with $70 \%$ FA, which was then sonicated and ultracentrifuged for 1 hour at 100,000 $\times$ g. The insoluble fraction was calculated as the difference between total and soluble $A \beta$. For analysis of 17 month old mice, we undertook a more direct approach for measurement of insoluble $A \beta$ by resuspending the remaining pellet following DEA fractionation in $70 \% \mathrm{FA}$, sonicating, and ultracentrifuging to yield the insoluble $A \beta$ fraction. Total $A \beta$ was calculated as the sum of measured soluble and insoluble $A \beta$. Sensitive and specific ELISAs to human $A \beta 1-40$ and $A \beta 1-42$ were purchased from IBL Transatlantic (Toronto, Canada) and conducted per the manufacturer's protocol.

\section{Cytokine ELISAs}

Levels of inflammatory cytokines IL $1 \beta$, TGF $\beta$, TNF $\alpha$, MCP-1, and IL4 were measured using Multiplex ELISA assays from Search Light Sample Testing Service (Pierce). Levels of SDF1 and RANTES were measured using ELISA kits from R \& D Systems (Minneapolis, $\mathrm{MN})$.

\section{Statistical analyses}

Immunoblots for PFA1 characterization were performed a minimum of three times. Immunoblots for phosphotau and total tau quantification were performed a minimum of two times for all samples collected. All statistics were calculated using GraphPad Prism 5 software, using student's t-test with significance determined as $\mathrm{p}<0.05$. Descriptive statistics are displayed as mean \pm S.E.M. Correlational analyses were performed on pairs of variables and the correlation is indicated as an $R^{2}$ value within a 95\% confidence interval, with $\mathrm{p}<0.05$.

\section{Results}

\section{PFA1 detects $A \boldsymbol{\beta}$ monomers and oligomers}

The monoclonal PFA1 antibody was designed and characterized to detect various forms of $A \beta$ [16]. To determine which $A \beta$ species from $A D 3 \times \operatorname{tg}$ mice are detected by PFA1, we performed an immunoblot of serum proteins and proteins extracted from brain homogenates of $3 \times \operatorname{tg}$ AD mice, with pure synthetic human $A \beta 40$ and $A \beta 42$ as positive controls. PFA1 (left panel) detected monomeric $A \beta 40$ and $A \beta 42$; however, PFA1 detected oligomeric forms of $A \beta 42$ with apparent higher affinity than $A \beta 40$ (Fig. 1). The major $A \beta$ species recognized by PFA1 in serum and in brain homogenates was the $56 \mathrm{kDa}$ complex $\mathrm{A} \beta * 56$, most likely a tetramer

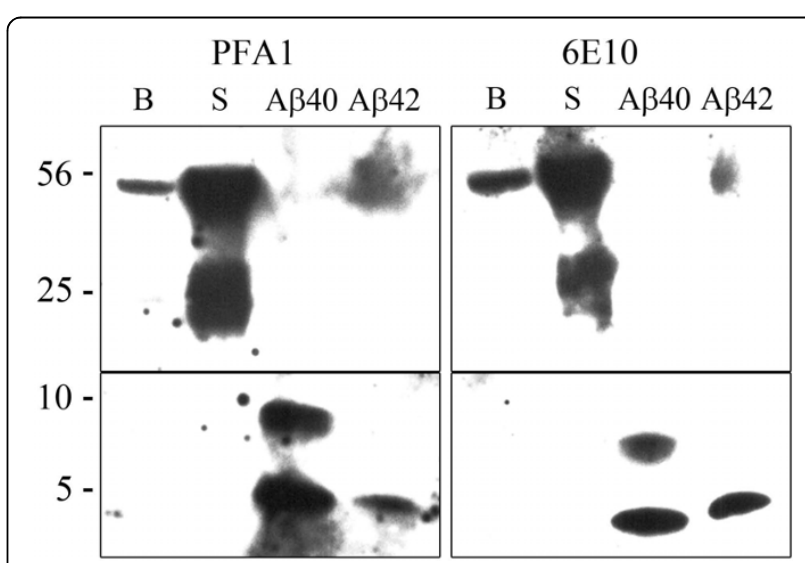

Figure 1 The protofibril monoclonal antibody PFA1 recognizes multiple $\mathbf{A} \boldsymbol{\beta}$ species. $5 \mu \mathrm{L}$ of serum (S) and $10 \mu \mathrm{g}$ of soluble protein extract from brains (B) of 22 month old $A D 3 \times$ tg mice were immunoblotted for $A \beta$ with antibody PFA1 (left) or 6 E10 (right). $1 \mu \mathrm{M}$ synthetic $A \beta 40$ and $A \beta 42$ (right lanes) were loaded for comparison. Membranes were cut at $15 \mathrm{kDa}$ to subject the lower panels to a longer exposure for detection purposes. PFA1 detected the $56 \mathrm{kDa}$ oligomeric form of $A \beta$ from serum with high affinity, similar to $6 \mathrm{E} 10$. 
of $A \beta$ trimers thought to be the leading culprit inducing memory deficits in an animal model of AD [6]. The monoclonal antibody 6E10 (right panel) similarly recognized multiple species of $A \beta$ - comparable to those detected by PFA1. Membranes probed with both PFA1 (left) and 6E10 (right) were cut at $\sim 15 \mathrm{kDa}$ so that the lower panels could be subjected to longer exposures. These studies demonstrate that the PFA1 antibody detects both monomeric and oligomeric forms of $A \beta$ derived from $3 \times \operatorname{tg} \mathrm{AD}$ mice.

\section{Total brain $A \beta$ is decreased in immunized 22 month old male mice}

To determine whether passive immunization of aged $3 \times$ tg AD mice decreased brain $\mathrm{A} \beta$, we administered weekly intravenous injections of PFA1 (100 $\mu \mathrm{g} /$ mouse/week) to 22 month-old male and female mice for four weeks. Brain homogenates were analyzed for DEA-soluble and total (FA extracted) $A \beta 40$ and $A \beta 42$. Insoluble $A \beta$ was calculated as the difference between total and soluble $A \beta$. We found no significant differences in soluble, insoluble, or total $A \beta 40$ and $A \beta 42$ in female mice immunized with PFA1 (Fig. 2A \& 2B). In contrast, we found a significant $48 \%$ decrease in insoluble $A \beta 42$, a significant $47 \%$ decrease in total $A \beta 42$, and a downward trend in soluble $A \beta 42$ (32\%) following treatment of immunized male mice at the same age (Fig. 2D). We found similar trends of decreased $A \beta 40$, in both the soluble (30\%) and insoluble (16\%) fractions from male mice (Fig. 2C). Relative values between females and males for $A \beta 40$ and A $\beta 42$ were as expected, with females showing higher levels of $A \beta 40$ (60-70 $\mathrm{pmol} / \mathrm{g}$ tissue) compared to males (15-20 pmol/g tissue) and higher levels of A $\beta 42$ (30-40 $\mathrm{pmol} / \mathrm{g}$ tissue) compared to males (9-14 $\mathrm{pmol} / \mathrm{g}$ tissue). These data reveal that passive immunization with PFA1 decreased brain $A \beta$ levels in male, but not female, 22 month-old $3 \times \operatorname{tg}$ AD mice.

\section{Plasma $A \beta$ is increased in immunized 22 month old male mice}

Plasma A $\beta$ levels were measured before and after the 4 week treatment paradigm to determine whether PFA1 sequestered $A \beta$ in the periphery. There was a significant $44 \%$ decrease $(\mathrm{p}<0.01)$ in plasma $A \beta 40$ levels in 22 month-old immunized female mice, and no differences in plasma $A \beta 42$ levels following treatment (Fig. 3A and $3 B)$. However, there was a significant $128 \%$ increase ( $\mathrm{p}<$ 0.05 ) in plasma $A \beta 40$ in males after treatment (Fig. 3C). Male mice also showed a similar increasing but non-significant trend (133\%) in plasma A $\beta 42$ following treatment (Fig. 3D). These data provide evidence for peripheral $A \beta$ sequestration in 22 month-old male mice through a decrease in brain $\mathrm{A} \beta$ with a corresponding increase in plasma $A \beta$.
CNS TNF $\alpha$ and MCP-1 levels are increased in immunized 22 month old female mice, and unchanged in 22 month old male mice

Passive immunization to $A \beta$ /amyloid may activate microglia since a small fraction of antibody delivered intravenously may penetrate the blood-brain barrier. To determine whether passive immunization induced neuroinflammatory responses, we examined cytokines and chemokines in brain homogenates of 22 month old $3 \times$ $\operatorname{tg} \mathrm{AD}$ mice following four weeks of treatment, including Interleukin-1 $\beta$ (IL-1 $\beta$ ), Transforming Growth Factor $\beta$ (TGF $\beta)$, Tumor Necrosis Factor $\alpha$ (TNF $\alpha)$, Monocyte Chemotactic Protein-1 (MCP-1, now CCL2, Chemokine (C-C) motif ligand 2), Interleukin-4 (IL-4), stromal cellderived factor-1 (SDF1), and Chemokine (C-C) motif ligand 5 (CCL5, or RANTES). Immunized females exhibited markedly increased levels of CNS TNF $\alpha$ (by $459 \%, \mathrm{p}<0.05$ ) and MCP-1 (by 83\%, p < 0.05) compared to PBS-treated mice (Fig. 4A). In contrast, immunized male mice showed no significant differences in cytokine levels compared to PBS-treated mice (Fig. 4B). These data suggest a significant neuroinflammatory response to passive immunization in female but not male mice at 22 months old.

\section{TGF $\beta$ and SDF1 are negatively correlated with brain $A \beta$,} while TNF $\alpha$ and MCP-1 are positively correlated

Certain proinflammatory cytokines and chemokines are up-regulated in human AD brain, such as TNF $\alpha$ and IL1, while others are down-regulated. To determine whether specific CNS cytokine levels correlated with brain A $\beta$ levels in 22 month-old female or male $3 \times$ tg AD mice, we performed the following correlation analyses. As soluble $A \beta 40$ or $A \beta 42$ increased, TGF $\beta$ and SDF1 decreased in females (Fig. 5A \& 5B). In addition, as insoluble and total $\mathrm{A} \beta 40$ increased, $\mathrm{TNF} \alpha$ also increased in males (data not shown, and Fig. 5C). When data from female and male mice were combined, we again found that TNF $\alpha$ and soluble $A \beta 40$ and $A \beta 42$ were positively correlated, and in addition, MCP-1 and all species of $\mathrm{A} \beta 40$ (soluble, insoluble, and total) and soluble A $\beta 42$ were also positively correlated (Fig. 5D-F). Collectively, these data reveal a consistent positive correlation of brain $A \beta$ levels with the proinflammatory cytokines TNF $\alpha$ and MCP-1, and a negative correlation of $\mathrm{A} \beta$ with TGF $\beta$ and SDF-1.

Immunized males show a decreased trend in phospho-tau As demonstrated above, PFA1 immunization decreased A $\beta$ levels in male $3 \times$ tg AD mice, which express three mutant human transgenes - APP, PS-1, and Tau. Therefore, we determined whether PFA1 immunization also affects hTau pathology. To test this, we examined phospho-tau and total tau levels in PFA1-treated versus 


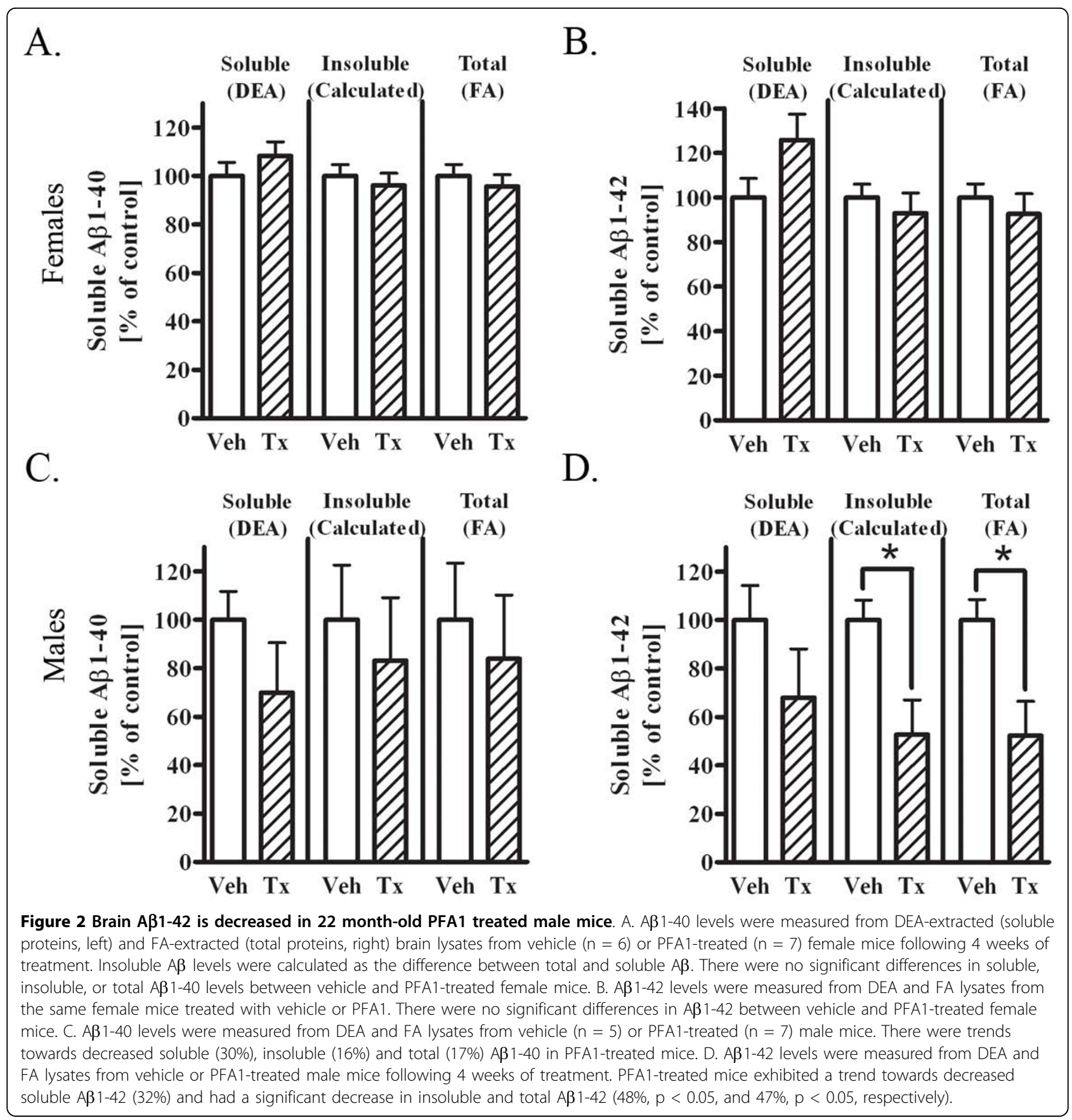

PBS-treated mice. We found no difference in phosphotau normalized to total tau in immunized female mice (Fig. 6A). However, we found a decreasing but nonsignificant trend (18\%) in phospho-tau in immunized males, suggesting that passive immunization may have a downstream beneficial effect on phospho-tau (Fig. 6B). In aggregate, these data reveal that passive immunization of 22 month old $3 \times \operatorname{tg} \mathrm{AD}$ mice resulted in decreased brain $A \beta$ and increased serum $A \beta$ with no change in CNS inflammatory cytokines in male mice, while in female mice with greater amyloid burden we found no effect on either brain or serum $A \beta$, and accompanied increased CNS proinflammatory cytokine levels.

\section{Immunized 17 month old female mice reveal a}

\section{decreasing trend in brain $A \beta$}

We wished to determine whether these results were due either to sex or to amyloid burden, as the female $3 \times \operatorname{tg}$ AD mice have a significantly greater amyloid load compared to male mice of the same age [18]. Therefore, we 

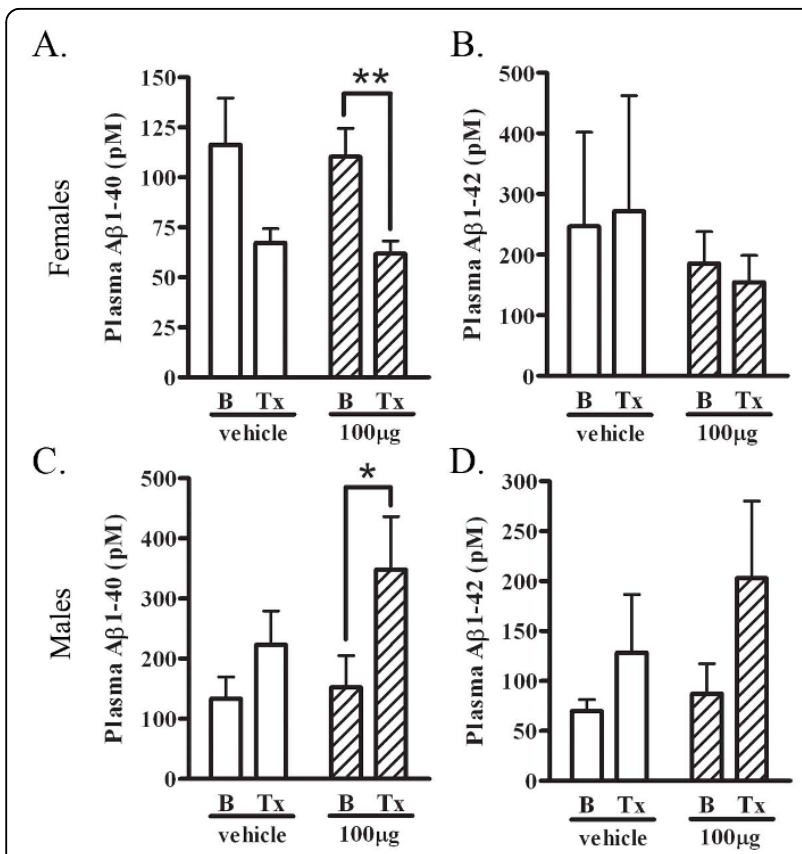

Figure 3 Plasma $A \beta$ is decreased in 22 month old PFA1 treated female mice and increased in 22 month old PFA1 treated male mice. A. A 1 1-40 levels were measured from plasma collected from vehicle and PFA1 treated female mice before and after 4 weeks of treatment. There was no significant change in plasma A $\beta$ 1-40 levels following treatment in vehicle treated animals. There was a significant $44 \%$ decrease $(p<0.01$ ) in plasma $A \beta 1-40$ levels following PFA1 treatment. B. A $\beta$ 1-42 levels were measured from plasma collected from vehicle and PFA1 treated female mice before and after treatment. There were no significant changes to $A \beta 1-42$ in either the vehicle or PFA1 group following treatment. C. A 1-40 levels were measured from plasma collected from vehicle and PFA1 treated male mice before and after 4 weeks of treatment. There was no significant change in plasma $A \beta 1-40$ levels following treatment in vehicle treated male mice. There was a significant $128 \%$ increase $(p<0.05)$ in $A \beta 1-40$ levels following treatment in the PFA1 treated male mice. D. A $\beta$ 1-42 levels were measured from plasma collected from male mice before and after vehicle or PFA1 treatment. There were no significant changes to $A \beta 1-42$ levels following treatment in either vehicle or PFA1 group.

conducted identical experiments with a younger - 17 month old - cohort of female mice. We hypothesized that if the treatment was effective only in male mice due to milder burden of pathology, then younger female mice with reduced pathology may exhibit similar responses. We performed the same 4-week passive immunization treatment with PFA1 on 17 month-old female $3 \times \operatorname{tg} \mathrm{AD}$ mice, and determined brain levels of soluble and insoluble $A \beta 40$ and $A \beta 42$, and calculated total $A \beta$ from the sum of soluble and insoluble $A \beta$. Immunized 17 month old female mice revealed a trend towards decreased soluble and insoluble A $\beta 40(25 \%$ soluble, $17 \%$ insoluble) and $A \beta 42$ (32\% soluble, $24 \%$ insoluble) following treatment (Fig. 7A \& 7B). These

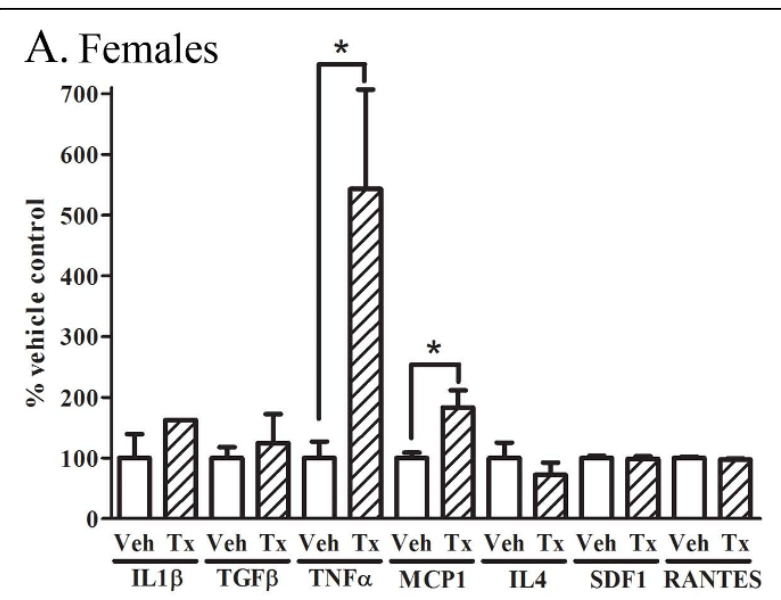

B. Males

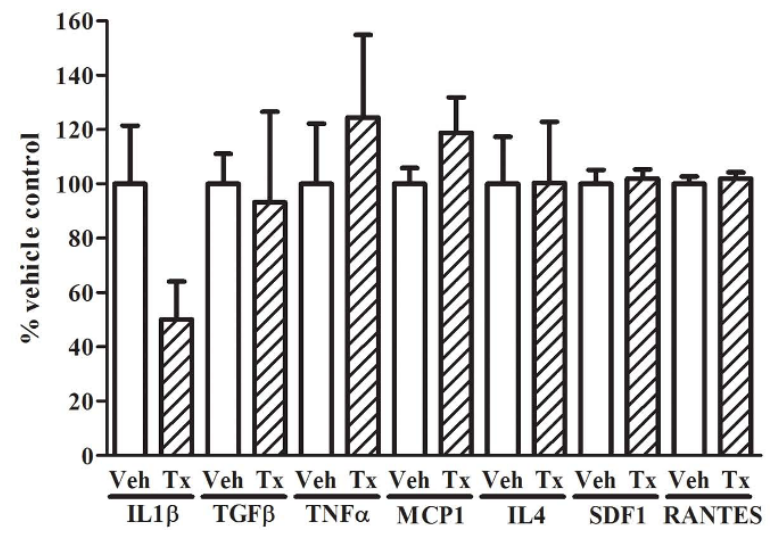

Figure 4 CNS TNF $\alpha$ and MCP-1 levels are increased in 22 month old immunized female mice and unchanged in male mice. $A$. Levels of inflammatory cytokines IL1 $\beta$, TGF $\beta$, TNF $\alpha$, MCP-1, IL4, SDF1, and RANTES were measured from brain homogenates of vehicle or PFA1 treated female mice. There were no significant differences in IL1 $\beta, T G F \beta, I L 4, S D F 1$, or RANTES between vehicle and PFA1 treated groups. There was a significant 459\% ( $p<0.05)$ increase in TNF $\alpha$, and an $83 \%$ increase $(p<0.05)$ in MCP-1 following PFA1 treatment in female mice. $B$. Levels of inflammatory cytokines IL $1 \beta, T G F \beta, T N F \alpha$, MCP-1, IL4, SDF1, and RANTES were measured from brain homogenates of vehicle or PFA1 treated male mice. There were no significant differences in any of the cytokines assayed.

data suggest that disease-burden, and not sex, may be the primary factor driving discrepant results we found in 22 month old male versus female mice.

\section{Plasma $A \beta$ is increased in immunized 17 month old female mice}

Next, we determined whether plasma $A \beta$ levels were affected by immunization. We measured plasma $A \beta$ levels from blood collected before and after the 4 week treatment paradigm. We found that PFA1-immunized 17 month old female mice revealed a significant $34 \%$ increase in $A \beta 42(\mathrm{p}<0.05)$, and an increasing trend $(140 \%)$ in $A \beta 40$, following treatment (Fig. 8A \& 8B). 


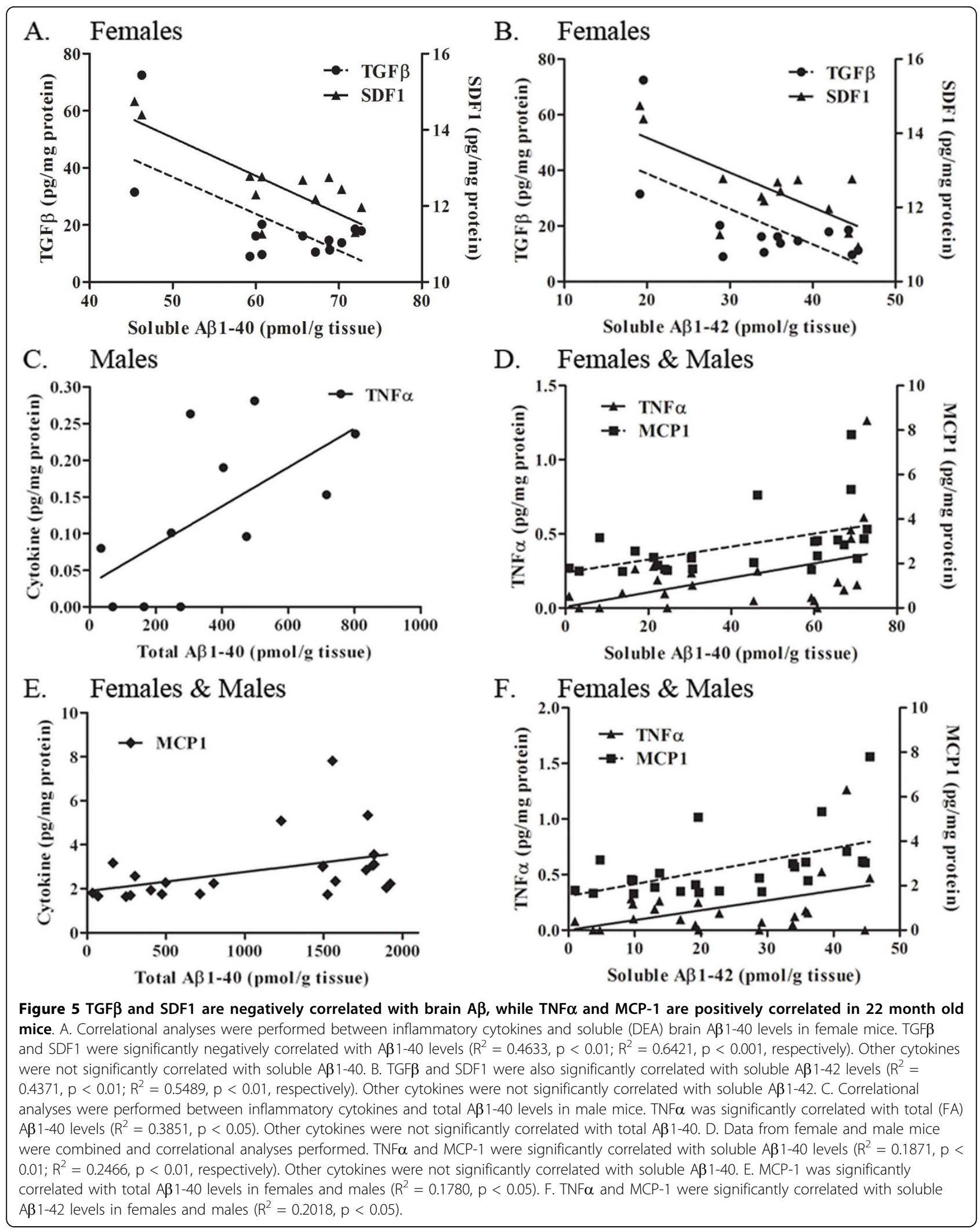




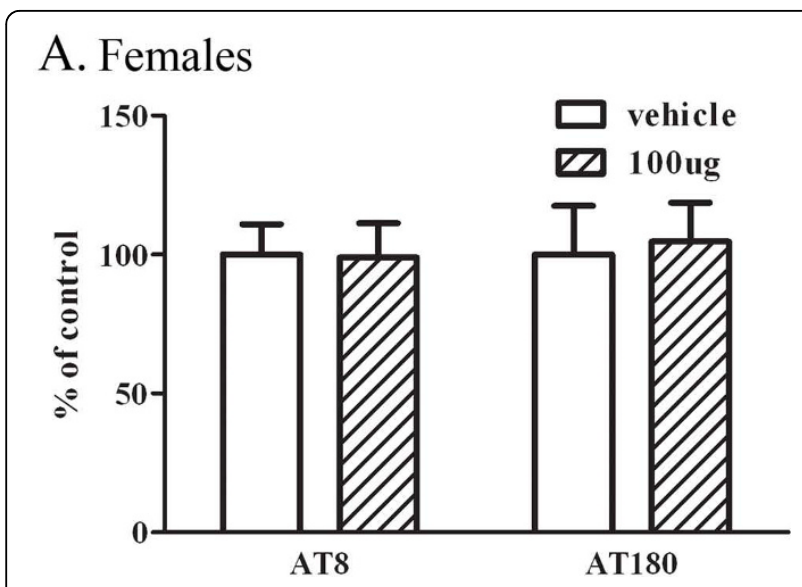

B. Males

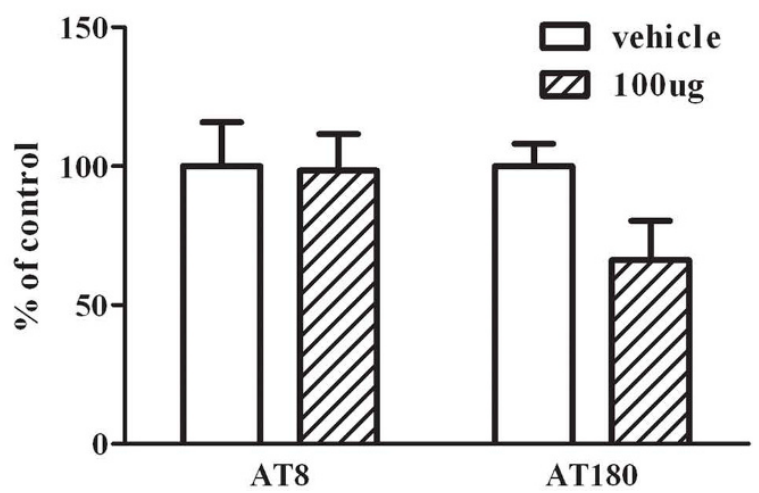

Figure 6 PFA1 treated 22 month old male, but not female, mice show a decreased trend in phospho-tau. A. Brain homogenates from PFA1-treated 22 month old female mice were Western blotted for phospho-tau (AT8, AT180) or total tau. PFA1treated female mice did not show any significant differences in phospho-tau by either AT8 or AT180 normalized to total tau levels. B. Brain homogenates from PFA1-treated 22 month old male mice were Western blotted for phospho-tau or total tau. PFA1-treated male mice showed a trend towards decreased phospho-tau by AT180 normalized to total tau (66\%) compared to vehicle-treated controls.

MCP-1 is decreased, and is positively correlated with brain $A \beta$, in immunized 17 month old female mice

PFA1 immunization significantly increased the levels of TNF $\alpha$ and MCP1 in 22 month old female mice. Therefore, we determined whether cytokine levels were altered with immunization in the 17 month old group of female mice. To test this, we measured brain levels of MCP-1, IL-10, SDF-1, and RANTES in PBS-treated versus PFA1-treated groups. The immunized female mice had a significant $26 \%$ decrease in MCP-1 following treatment ( $<$ 0.05) (Fig. 9A).

Finally, we determined whether specific CNS cytokines were consistently correlated with brain $A \beta$ levels, and found that MCP-1 decreased as soluble, insoluble, and total $A \beta 40$ in female mice decreased $\left(R^{2}=0.45\right.$, $\mathrm{p}<0.05 ; \mathrm{R}^{2}=0.615, \mathrm{p}<0.01, \mathrm{R}^{2}=0.764, \mathrm{p}<0.01$, respectively) (Fig. 9B-D). This data is consistent with results found with the 22 month old mice.

\section{Discussion}

Here, we examined the efficacy of a passive immunization paradigm using the monoclonal antibody PFA1 in reducing brain $A \beta$ in a triple transgenic model of $A D$. We first demonstrate that the antibody binds to both $A \beta 40$ and $A \beta 42$ species, and binds to both oligomeric and monomeric forms (Fig. 1). Chronic passive immunization of 22 month-old $3 \times \operatorname{tg} A D$ mice resulted in a significant decrease in brain $A \beta$ accompanied by an increase in serum $A \beta$ in male mice with intermediate (less advanced) A $\beta$ /amyloid pathology (Fig. 2, 3). However, immunization of 22 month-old female $3 \times \operatorname{tg} A D$ mice with advanced $A \beta$ pathology had no effect on reducing brain $\mathrm{A} \beta$ while increasing levels of inflammatory cytokines TNF $\alpha$ and MCP-1 (Fig. 2, 3, 4). These effects were presumably pathology burden- and not sexdependent, as immunization of 17 month-old female mice with intermediate pathology resulted in trends towards decreased brain $A \beta$, increased clearance of $A \beta$ to the periphery, and a decrease in the inflammatory cytokine MCP-1 (Figs. 7, 8, 9).

We demonstrated a significant reduction in total $A \beta 42$ in immunized 22 month-old male $3 \times \operatorname{tg} \mathrm{AD}$ mice. Although effects on total $A \beta 40$ or soluble $A \beta 40$ or A $\beta 42$ were not statistically different, all species of $A \beta$ showed a consistent trend towards decreased $A \beta$ following passive immunization. Similarly, 17 month-old female $3 \times \operatorname{tg} \mathrm{AD}$ mice showed consistent, but non-significant, trends toward decreased $A \beta$ of all forms. These results were in contrast to those observed in the 22 month-old females, where there was no evidence of decreased $A \beta$ of any species, with a possible increase in soluble $A \beta 42$. While our results suggest that there may be an effect of PFA1 passive immunization on reducing all forms of brain $A \beta$ at intermediate pathological stages, it will be necessary to expand the size and scope of this study due to address this issue.

The peripheral sink hypothesis of $A \beta$ clearance suggests that increasing $A \beta$-binding agents in the periphery enhances $A \beta$ efflux from the brain $[14,22]$. In our studies, we observed a concurrent increase in serum $A \beta$ with a decrease in brain $A \beta$ in 22 month-old male mice, and a concurrent increase in serum $A \beta$ with a trend towards decreased brain $A \beta$ in 17 month-old female mice. Our findings support the possibility that both passive and active immunization involve antibody-mediated clearance of $A \beta$ from the brain to the periphery. This effect can occur independently of an antibody effect in the brain which may incite microglial phagocytosis. A $\beta$ binding agents, not limited to antibodies, such as 


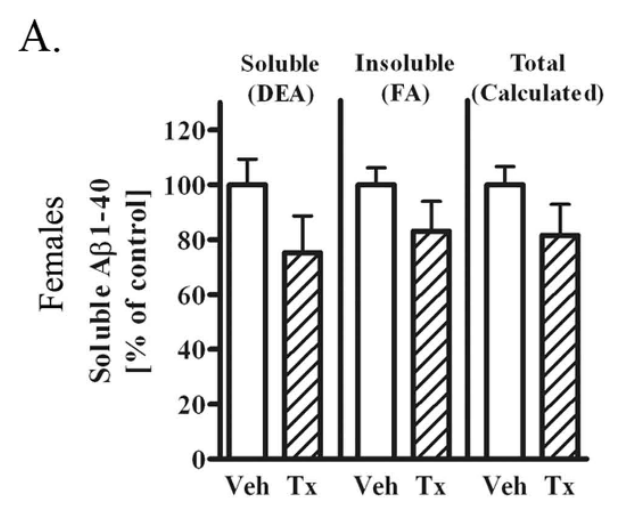

B.

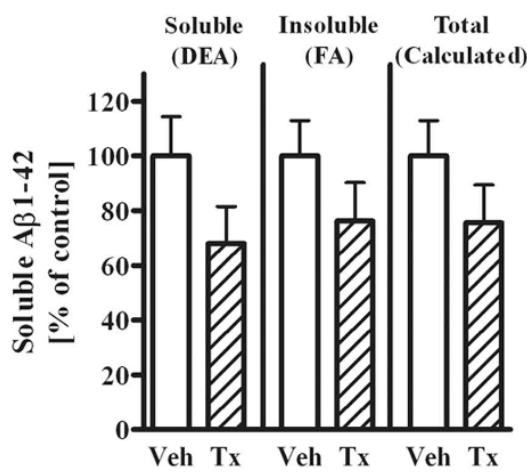

Figure 717 month-old PFA1-treated female mice show trends towards decreased brain $\mathbf{A} \boldsymbol{\beta} 40$ and $\mathbf{A} \boldsymbol{\beta} 42$. A. A $\beta 1-40$ levels were measured from DEA-extracted (soluble proteins, left) and FA-extracted (insoluble, middle) brain lysates from vehicle $(n=5)$ or PFA1-treated $(n=5) 17$ month-old female mice. Total $A \beta$ levels were calculated as the sum of soluble and insoluble $A \beta$ levels. There was a trend towards decreased soluble (25\%) and insoluble (17\%) A 1-40 levels in PFA1-treated female mice. B. A 1-42 levels were measured from DEA and FA lysates from the same female mice treated with vehicle or PFA1. There was a trend towards decreased soluble (32\%) and insoluble (24\%) AB1-42 levels in PFA1treated female mice.

heparin [23] and the Nogo receptor [24], are also effective in reducing brain $A \beta$. In addition, active immunization of an $\mathrm{AD}$ mouse model lacking the FcR, which is necessary for immune activation, still reduces brain $\mathrm{A} \beta$ [25], and deglycosylated antibodies, which do not bind the FcR, increase $A \beta$ clearance to the periphery [26]. These findings suggest that peripheral clearance of $A \beta$ is a viable mechanism by which passive or active immunization may decrease brain $A \beta$ levels.

Although passive immunization does not directly involve $\mathrm{T}$-cell activation, it can still induce microglial
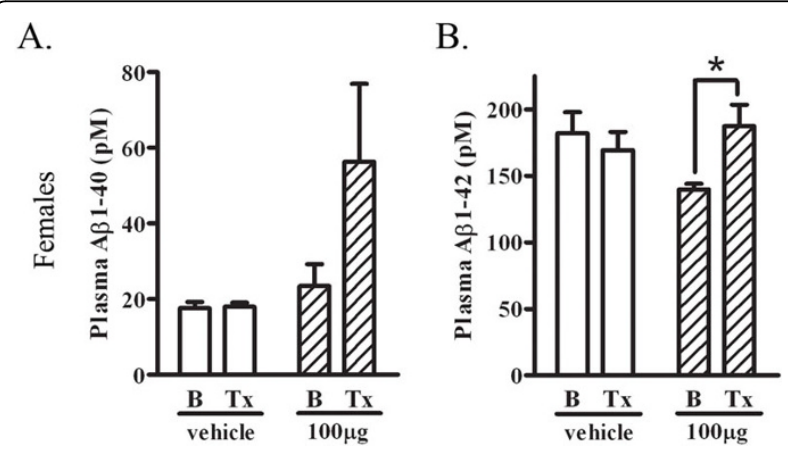

Figure 8 Plasma $A \beta$ is increased in 17 month-old PFA1-treated female mice. A. A $\beta$ 1-40 levels were measured from plasma collected from vehicle and PFA1 treated 17 month-old female mice before and after 4 weeks of treatment. There was no significant change in plasma $A \beta 1-40$ levels following treatment in vehicle treated animals. There was a trend towards increased A $\beta$ 1-40 levels in PFA1-treated female mice (140\%) after 4 weeks of treatment. B. A $\beta$ 1-42 levels were measured from plasma collected from 17 month-old vehicle and PFA1 treated female mice before and after treatment. There were no significant changes to $A \beta 1-42$ in vehicletreated animals, but a significant 34\% increase $(p<0.05)$ in PFA1treated animals following treatment. activation and upregulation of inflammatory cytokines. Indeed, we observed that the inflammatory cytokine TNF $\alpha$ and chemokine MCP-1 were increased following immunization in 22 month-old female mice in the absence of any benefit on lowering brain $A \beta$. TNF $\alpha$ is increased in human AD brains [27] and is increased following antibody treatment in cultured cells [26]. MCP-1 is a chemokine which is also upregulated in serum of AD patients and may play a role in early inflammatory events [28]. The effects of microglial activation may be pathology-dependent, as TNF $\alpha$ induction in younger PS1xAPP mice results in microglial phagocytosis while activation at older ages results in cytotoxic effects [29]. Thus, immune modulation at advanced pathology may increase potentially adverse inflammatory effects of microglial activation compared to a neuroprotective phagocytic $A \beta /$ amyloid clearance effect found with lower disease burden.

In addition to the increased cytokine levels following passive immunization in mice with advanced pathology, we also observed significant positive correlations between increasing $A \beta$ levels and increasing TNF $\alpha$ and MCP-1 levels, further supporting a pro-inflammatory role for these cytokines. In contrast, we observed an inverse correlation with other cytokines - as $A \beta$ levels increased, TGF $\beta$ and SDF1 decreased, implicating a beneficial role for these cytokines in mediating anti-A $\beta$ effects. This hypothesis is supported by evidence that overexpressing TGF $\beta$ in hAPP mice results in decreased numbers of plaques [30] and reducing TGF $\beta$ signaling in mice results in increased $A \beta$ accumulation and neurodegeneration [31]. Expression of the chemokine SDF1 is decreased in early AD brains [32], suggesting that disregulation of its chemotactic signaling properties may 


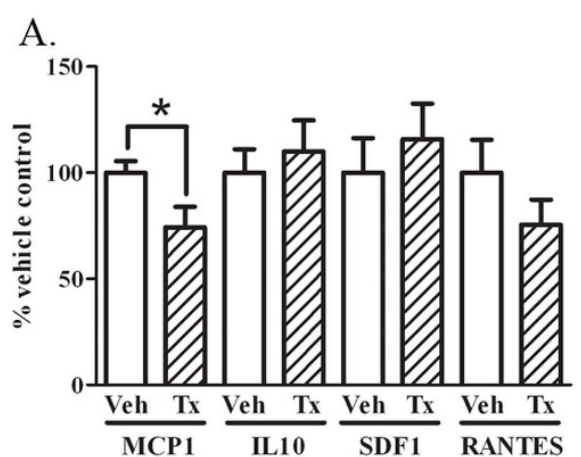

C.

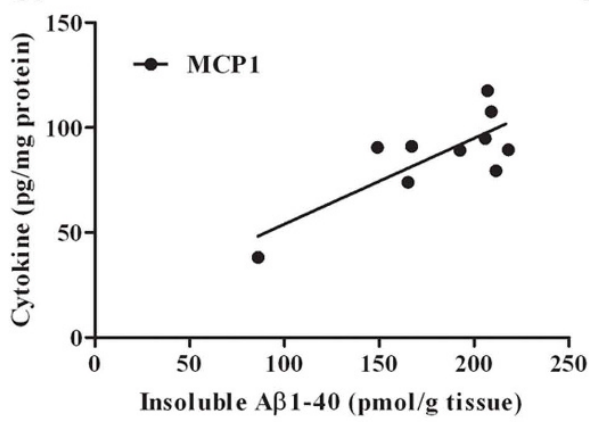

B.

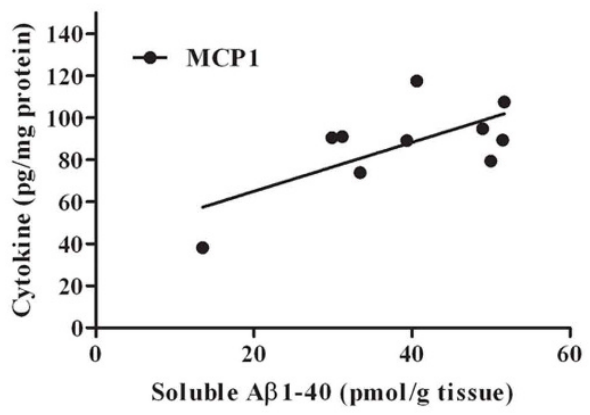

D.

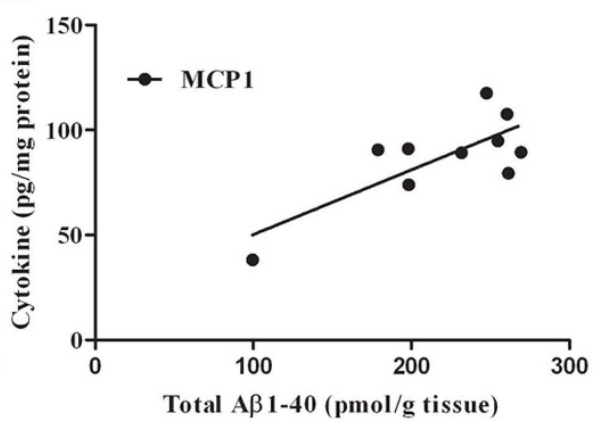

Figure 9 CNS MCP-1 is decreased, and is positively correlated with brain A $\boldsymbol{\beta}$ levels, in 17 month-old female mice. A. Levels of inflammatory cytokines MCP-1, IL10, SDF1, and RANTES were measured from brain homogenates of 17 month-old vehicle or PFA1 treated female mice. There were no significant differences in IL10, SDF1, or RANTES between vehicle and PFA1 treated groups. There was a significant 26\% $(p<0.05)$ increase in MCP1 following PFA1 treatment in female mice. B. Correlational analyses were performed between inflammatory cytokines and soluble (DEA) brain A 1 1-40 levels in female mice. MCP1 was significantly positively correlated with soluble $A \beta 1-40$ levels $\left(R^{2}=\right.$ $0.4553, p<0.05)$. Other cytokines were not significantly correlated with soluble A $\beta 1-40$. C. MCP1 was also significantly correlated with insoluble A $\beta 1-40$ levels $\left(R^{2}=0.6149, p<0.01\right)$. Other cytokines were not significantly correlated with insoluble A $\beta 1-40$. D. MCP1 was significantly correlated with the calculated levels of total $A \beta 1-40$ levels $\left(R^{2}=0.5835, p<0.01\right)$.

either be an early symptom of $\mathrm{AD}$ or may contribute to later $\mathrm{AD}$ pathology.

\section{Conclusions}

In conclusion, our study is the first to establish pathology burden-dependent effects of passive immunization in an animal model of AD. Treatment at an intermediate pathological stage is more effective at reducing brain $A \beta$, while treatment at a more advanced stage induces neuroinflammatory effects. In addition, our findings support previous studies that passive immunization, as well as active immunization, results in the clearance of $A \beta$ from the brain to the periphery. High levels of $A \beta$ pathology may contribute to neurotoxic effects mediated by microglial inflammation, while immunomodulation at an intermediate stage may allow the larger pool of soluble $A \beta$ to be sequestered into the periphery. These findings highlight the importance of considering disease burden in determining optimal passive immune timing and dosage in order to maximize therapeutic effects and minimize adverse effects when considering a human intervention.

\section{Abbreviations used}

APP: amyloid precursor protein; AD: Alzheimer's disease; DEA: diethylamine; FA: formic acid; IL $1 \beta$ : interleukin $1 \beta$; TGF $\beta$ : transforming growth factor $\beta$; TNF $\alpha$ : tumor necrosis factor $\alpha$; MCP1: monocyte chemotactic protein 1; SDF1: stromal cell-derived factor 1; CCL5: chemokine ligand 5, RANTES

\section{Competing interests}

The authors declare that they have no competing interests.

\section{Authors' contributions}

SSM, ES, SA, MS, TN, JSP, and RW conducted experiments. SSM, HSH, and RST prepared the manuscript. CD, YM and RST conceived the project and designed experiments. IM, FB, and GWR provided valuable scientific input, and RST supervised the overall project. All authors have read and approved the final manuscript.

\section{Acknowledgements}

We thank Dr. Paul Patterson, Jan Ko, and Susan Ou at Caltech for production of the PFA1. This work was supported by NIH grants NS059178 (SSM), R01 AG026478 (RST), and the Intramural Research Program of the NIH, National Institute on Aging (FB). 


\section{Author details}

'Department of Neuroscience, Georgetown University Medical Center, 3970 Reservoir Road NW, Washington, DC 20057, USA. ${ }^{2}$ Department of Neurology, Bldg. D, Suite 177, Georgetown University Medical Center, 4000 Reservoir Road NW, Washington, DC 20057, USA. ${ }^{3}$ National Institutes of Health, Bethesda, MD, USA. ${ }^{4}$ Department of Pharmacology, Case Western Reserve University, 10900 Euclid Ave., Cleveland, OH 44106, USA. ${ }^{5}$ Structural Biology Department and Pittsburgh Institute for Neurodegenerative Diseases, Pittsburgh, PA 15260, USA.

Received: 31 August 2010 Accepted: 28 September 2010 Published: 28 September 2010

\section{References}

1. Selkoe DJ: Alzheimer's disease: genes, proteins, and therapy. Physiol Rev 2001, 81:741-766.

2. Jarrett JT, Berger EP, Lansbury PT Jr: The C-terminus of the beta protein is critical in amyloidogenesis. Ann N Y Acad Sci 1993, 695:144-148.

3. Jarrett JT, Berger EP, Lansbury PT Jr: The carboxy terminus of the beta amyloid protein is critical for the seeding of amyloid formation: implications for the pathogenesis of Alzheimer's disease. Biochemistry 1993, 32:4693-4697.

4. Hsia AY, Masliah E, McConlogue L, Yu GQ, Tatsuno G, Hu K, Kholodenko D, Malenka RC, Nicoll RA, Mucke L: Plaque-independent disruption of neural circuits in Alzheimer's disease mouse models. Proc Natl Acad Sci USA 1999, 96:3228-3233.

5. Townsend M, Shankar GM, Mehta T, Walsh DM, Selkoe DJ: Effects of secreted oligomers of amyloid beta-protein on hippocampal synaptic plasticity: a potent role for trimers. J Physiol 2006, 572:477-492.

6. Lesne S, Koh MT, Kotilinek L, Kayed R, Glabe CG, Yang A, Gallagher M, Ashe $\mathrm{KH}$ : A specific amyloid-beta protein assembly in the brain impairs memory. Nature 2006, 440:352-357.

7. Lue LF, Kuo YM, Roher AE, Brachova L, Shen Y, Sue L, Beach T, Kurth JH, Rydel RE, Rogers J: Soluble amyloid beta peptide concentration as a predictor of synaptic change in Alzheimer's disease. Am J Pathol 1999, 155:853-862.

8. McLean CA, Cherny RA, Fraser FW, Fuller SJ, Smith MJ, Beyreuther K, Bush Al, Masters CL: Soluble pool of Abeta amyloid as a determinant of severity of neurodegeneration in Alzheimer's disease. Ann Neurol 1999, 46:860-866.

9. Janus C, Pearson J, McLaurin J, Mathews PM, Jiang Y, Schmidt SD, Chishti MA, Horne P, Heslin D, French J, et al: A beta peptide immunization reduces behavioural impairment and plaques in a model of Alzheimer's disease. Nature 2000, 408:979-982.

10. Schenk D, Barbour R, Dunn W, Gordon G, Grajeda H, Guido T, Hu K, Huang JP, Johnson-Wood K, Khan K, et al: Immunization with amyloidbeta attenuates Alzheimer disease-like pathology in the PDAPP mouse. Nature 1999, 400:173-177.

11. Morgan D, Diamond DM, Gottschall PE, Ugen KE, Dickey C, Hardy J, Duff K, Jantzen P, DiCarlo G, Wilcock D, et al: A beta peptide vaccination prevents memory loss in an animal model of Alzheimer's disease. Nature 2000, 408:982-985

12. Orgogozo JM, Gilman S, Dartigues JF, Laurent B, Puel M, Kirby LC, Jouanny P, Dubois B, Eisner L, Flitman $S$, et al: Subacute meningoencephalitis in a subset of patients with $A D$ after $A$ beta 42 immunization. Neurology 2003, 61:46-54.

13. Bard F, Cannon C, Barbour R, Burke RL, Games D, Grajeda H, Guido T, Hu K, Huang JP, Johnson-Wood $K$, et al: Peripherally administered antibodies against amyloid beta-peptide enter the central nervous system and reduce pathology in a mouse model of Alzheimer disease. Nature Medicine 2000, 6:916-919.

14. DeMattos RB, Bales KR, Cummins DJ, Dodart JC, Paul SM, Holtzman DM: Peripheral anti-A beta antibody alters CNS and plasma A beta clearance and decreases brain A beta burden in a mouse model of Alzheimer's disease. P Natl Acad Sci USA 2001, 98:8850-8855.

15. Salloway S, Sperling R, Gilman S, Fox NC, Blennow K, Raskind M, Sabbagh M, Honig LS, Doody R, van Dyck CH, et al: A phase 2 multiple ascending dose trial of bapineuzumab in mild to moderate Alzheimer disease. Neurology 2009, 73:2061-2070.

16. Gardberg AS, Dice LT, Ou S, Rich RL, Helmbrecht E, Ko J, Wetzel R, Myszka DG, Patterson PH, Dealwis C: Molecular basis for passive immunotherapy of Alzheimer's disease. Proc Natl Acad Sci USA 2007, 104:15659-15664.

17. Gardberg A, Dice L, Pridgen K, Ko J, Patterson P, Ou S, Wetzel R, Dealwis C: Structures of Abeta-related peptide-monoclonal antibody complexes. Biochemistry 2009, 48:5210-5217.

18. Hirata-Fukae C, Li HF, Hoe HS, Gray AJ, Minami SS, Hamada K, Niikura T, Hua F, Tsukagoshi-Nagai H, Horikoshi-Sakuraba Y, et al: Females exhibit more extensive amyloid, but not tau, pathology in an Alzheimer transgenic model. Brain Res 2008, 1216:92-103.

19. Oddo S, Caccamo A, Shepherd JD, Murphy MP, Golde TE, Kayed R, Metherate R, Mattson MP, Akbari Y, LaFerla FM: Triple-transgenic model of Alzheimer's disease with plaques and tangles: intracellular Abeta and synaptic dysfunction. Neuron 2003, 39:409-421.

20. Planel E, Richter KE, Nolan CE, Finley JE, Liu L, Wen Y, Krishnamurthy P, Herman M, Wang L, Schachter JB, et al: Anesthesia leads to tau hyperphosphorylation through inhibition of phosphatase activity by hypothermia. J Neurosci 2007, 27:3090-3097.

21. Nishitomi K, Sakaguchi G, Horikoshi Y, Gray AJ, Maeda M, Hirata-Fukae C, Becker AG, Hosono M, Sakaguchi I, Minami SS, et al: BACE1 inhibition reduces endogenous Abeta and alters APP processing in wild-type mice. J Neurochem 2006, 99:1555-1563.

22. Lemere CA, Spooner ET, LaFrancois J, Malester B, Mori C, Leverone JF, Matsuoka Y, Taylor JW, DeMattos RB, Holtzman DM, et al: Evidence for peripheral clearance of cerebral Abeta protein following chronic, active Abeta immunization in PSAPP mice. Neurobiol Dis 2003, 14:10-18.

23. Bergamaschini L, Rossi E, Storini C, Pizzimenti S, Distaso M, Perego C, De Luigi A, Vergani C, De Simoni MG: Peripheral treatment with enoxaparin, a low molecular weight heparin, reduces plaques and beta-amyloid accumulation in a mouse model of Alzheimer's disease. J Neurosci 2004, 24:4181-4186.

24. Park JH, Gimbel DA, GrandPre T, Lee JK, Kim JE, Li W, Lee DH, Strittmatter SM: Alzheimer precursor protein interaction with the Nogo66 receptor reduces amyloid-beta plaque deposition. J Neurosci 2006, 26:1386-1395

25. Das P, Howard V, Loosbrock N, Dickson D, Murphy MP, Golde TE: Amyloidbeta immunization effectively reduces amyloid deposition in FcRgamma-/- knock-out mice. J Neurosci 2003, 23:8532-8538.

26. Takata K, Hirata-Fukae C, Becker AG, Chishiro S, Gray AJ, Nishitomi K, Franz AH, Sakaguchi G, Kato A, Mattson MP, et al: Deglycosylated antiamyloid beta antibodies reduce microglial phagocytosis and cytokine production while retaining the capacity to induce amyloid beta sequestration. Eur J Neurosci 2007, 26:2458-2468.

27. Fillit $H$, Ding WH, Buee L, Kalman J, Altstiel L, Lawlor B, Wolf-Klein G Elevated circulating tumor necrosis factor levels in Alzheimer's disease. Neurosci Lett 1991, 129:318-320.

28. Galimberti D, Fenoglio C, Lovati C, Venturelli E, Guidi I, Corra B, Scalabrini D, Clerici F, Mariani C, Bresolin N, Scarpini E: Serum MCP-1 levels are increased in mild cognitive impairment and mild Alzheimer's disease. Neurobiol Aging 2006, 27:1763-1768.

29. Jimenez S, Baglietto-Vargas D, Caballero C, Moreno-Gonzalez I, Torres M, Sanchez-Varo R, Ruano D, Vizuete M, Gutierrez A, Vitorica J: Inflammatory response in the hippocampus of PS1M146L/APP751SL mouse model of Alzheimer's disease: age-dependent switch in the microglial phenotype from alternative to classic. J Neurosci 2008, 28:11650-11661.

30. Wyss-Coray T, Lin C, Yan F, Yu GQ, Rohde M, McConlogue L, Masliah E, Mucke L: TGF-beta1 promotes microglial amyloid-beta clearance and reduces plaque burden in transgenic mice. Nat Med 2001, 7:612-618.

31. Tesseur I, Zou K, Esposito L, Bard F, Berber E, Can JV, Lin AH, Crews L, Tremblay P, Mathews $P$, et al: Deficiency in neuronal TGF-beta signaling promotes neurodegeneration and Alzheimer's pathology. J Clin Invest 2006, 116:3060-3069.

32. Laske C, Stellos K, Eschweiler GW, Leyhe T, Gawaz M: Decreased CXCL12 (SDF-1) plasma levels in early Alzheimer's disease: a contribution to a deficient hematopoietic brain support? J Alzheimers Dis 2008, 15:83-95.

doi:10.1186/1742-2094-7-57

Cite this article as: Minami et al.: Therapeutic versus neuroinflammatory effects of passive immunization is dependent on $A \beta \beta /$ amyloid burden in a transgenic mouse model of Alzheimer's disease. Journal of Neuroinflammation 2010 7:57. 